\title{
La fe del pueblo del Antiguo Testamento frente al sufrimiento (I). Los profetas: Jeremías, Habacuc e Isaías
}

\author{
Rafael de Sivatte, \\ Centro de Reflexión Teológica, \\ San Salvador.
}

\section{Planteamiento del problema}

\subsection{Importancia y actualidad de la pregunta por el sufrimiento y el mal}

Al escribir este articulo, el mundo entero ha podido comprobar cuánto es el sufrimiento y mal que somos capaces de provocar los seres humanos, especialmente contra seres indefensos y empobrecidos. La llamada "coalición" (formada por Estados Unidos, Inglaterra, España, Italia, también palses como El Salvador, y algunos otros), en contra de la voluntad de Naciones Unidas, ha declarado la guerra a Irak y amenaza con declararla a otros parses. Estos son considerados por aquellos como terroristas y son acusados, sin pruebas, de poseer amas de destrucción masiva, aunque los motivos reales parecen ser muy ouros, y están relacionados con la ambición de posesión y de poder, por parte de los miembros de la mencionada "coalición". El resultado ya hemos tenido ocasión de contemplarlo, en las imagenes de estos dias: dolor, sufrimiento, muerte y mal, provocados contra pobres inocentes, ancianos, mujeres y niños... No es de extrañar. por tanto, que nos preguntemos cuál es el origen del sufrimiento y del mal, y sobre todo cómo podemos enfrentar, desde la fe. este grave problema de la humanidad y qué tipo de explicaciones podemos dar.

Sin duda, entre el conjunto de los problemas e interrogantes de la existencia que la humanidad tiene planteados, el sufrimiento y el mal ocupan un lugar muy destacado e importante. En realidad, forman parte de la experiencia universal de la humanidad, aunque, obviamente, los grupos indefensos los padecen, por lo general, con mucha mayor fuerza. 
El sufrimienlo y el mal pueden ser provocados por la naturaleza. en forma de catástrofes naturales, enfermedades, muerle. Pero pueden ser provocados también por el mal uso y abuso de la libertad humana. en forma de injusticia. explotación, opresión, insolidaridad, desprecio de la vida del otro. violación de los derechos humanos, marginación. $Y$ esto en lodos los ámbilos de la rcalidad humana: personal, familiar, comunitario, social, religioso, nacional e internacional. Estos sufrimientos, productos de males "históricos", son los que hacen más agudo el problema y más acuciante la respuesta.

\section{2. Preocupación de todas las culturas y religiones}

Tan grande es la realidad del sufrimienlo y del mal que no ha dejado - ni deja- indiferenle a ninguna cultura mundial. Más bien, loda cultura ha buscado y sigue buscando una respuesta, y quiere explicar las causas. Asi, por ejemplo, iserá la retribución, la teoría que habla de premios y castigos por la conducta. la que explique dicha realidad o más bien habrá que comprender el sulrimiento como camino hacia la purificación y la vida elema, la cual seria la única que realmente imporla?

Además, práclicamente todas las culturas han relucionado. de algún modo, $\mathrm{cl}$ sufrimiento y el mal con la divinidad y proponen diversas explicaciones. Hagamos un breve recorrido. El sufrimiento y el mal serían causados por los espiritus malignos y sus magos; por el fatum, superior a dioses y seres humanos; por las ansias de felicidad, creadas por los dioses malos, pero irrealizables, y, por tanto, frustrantes; por la lucha entre dos principios divinos $\rightarrow$ l del bien y el del mal-, que acaba con frecuencia con el triunfo de éste; por las preferencias de los dioses, que los llevan a perjudicar a quienes no son sus preferidos. Serian pruebas pueslas caprichosamente por las divinidades o castigo divino por las faltas -incluso las inconscientes, que lambién producen desorden. $O$ serian una purificación provocada por los dioses, a lo largo de reencamaciones, que son necesarias hasta que el ser humano llegue a la perfección total y a la integración en la divinidad...

Ante estas realidades, la pregunts es también obvia: iqué puede y debe hacer el ser humano para evitur o no dejarse afectar por el sufrimiento y por el mal? ¿Aspirar a morir cuanto anles mejor, es decir, aspizar al hades? ¿Ahogar el sufrimiento y el mal con el placer? ¿Dominar con la voluntad los deseos y las pasiones para evitar las frusiraciones que llevan al sufrimiento? ¿Ganarse a los dioses con actos mágicos y, o religiosos?'.

1. Sobre lo dicho en los dos últimos párrafos, vease, por ejemplo, Juen Anlonio Esırada, Lo imparible readicea. Lo crisis de lo fe en Dios. Madrid. 1997; efr. también A. Gesche, "Le probleme du mal, probleme de socicle". Théologie de lo Libération, Annales Cardijn. Louvain-la-Neuve, 1985. 


\section{Moyor agudeza del problems en Israel}

Toda la problemálica planteada anteriormente sc convierte en más acuciante y crítica, en el pueblo de lsrael, pueblo creyente en Yahveh. ¿Por qué? En primer lugur, por su sentido monoleista, que no permite acudir a explicaciones basadas en la existencia de divinidades del mal. También por su experiencia histórica de un Dios bueno, proleclor, liberador, que siempre ha buscado la felicidad del pueblo. Finalmente, por su conciencia de situaciones de gran injuslicia y mal, sufridas por los justos, los pobres y los inocentes, y provocadas, además, por personas injustas, desaprensivas y que se aprovechan del projjimo indefenso'.

Es cierio que en los inicios, toda esta realidad de sufrimiento y mal no fue problema para Israel, dada su visión corporativista. Según esto, el grupo, el colectivo está por encima del individuo y, por ello, si el grupo sigue adelante, no es decisivo lo que le ocurre al individuo. Además, de acuerdo a esta visión, sería posible que un individuo sufra por acciones cometidas por otras personas del grupo, presentes o pasadas'.

El problema se hace agudo, cuando pierde fuerza esta visión corporativista y coleclivisı. Y esto ocurre en Israel' con el proceso de personalización, llevado a cabo por los profetas y los sabios. En ese proceso se aplica al individuo la doctrina de la retribución, del premio o casligo, según sus mérilos, y entonces, la experiencia contradice la lógica de la relribución personal. Por ejemplo, entre

2. Gerhard von Rad, "Las tribulaciones de Isracl y la consolación del individuo". Télogia del Amiguo Testamento. I. Teologia de las tradiciones históricas de Isracl. Salamanco, 1969, pp.469-508; Josć L Sicrc, "La cvolución sociocconómica de Isracl". "Con los pobres de la vierra". La justicia social en los profetas de Isracl. Madrid, 1984, pp. 48-83; Idem, “Conclusiones", op. cil., pp. 439-453.

3. Enirc olras icxtos, Gn 18, 24; Ex 21, 25; Pr 3, 31-.12; 10, 28; 11, 21; 23, 17.18; 24, 19; Sb I, 6; Si 7, 36; 16, 22; Jr 12, 1.5; 31, 29; Ez 14, 12; MI 2, 17; cfr. también Luc H. Grollenberg, "El problema de la retribución", Vision nueva de la Biblia, Barcelona, 1972 pp. 276-280; sobrc todo las argumentacioncs que presentarán los amigos dc Joh para explicar el sufrimicnto de éste. tal como veremos en la segunda parte de esic articulo.

4. Cfr. Di 7, 10; 24, 16; Jr 31, 29-30; Ez 14, 12-13; 18. Como cs sabido, Karl Jaspers afirma que la relativa independización de la persona, en relación con el grupo y sus condicionamicntos, acacció en un periodo indeıcrminado del primer milenio. que sc silúa en tomo al siglo VI, en áreas geograficas muy distintas y sin aparente relación cnirc si: China, India, Persia. Grecia c Isracl; ffr. Juan Mantin Velasco. "Melamorfosis de lo sagrado y fuluro del cristianismo", Selecciones de Teologfa, 150, 38 (1999), pp. 129 - 130. Cfr. tambićn Gemard von Rad, "Las tribulaciones de Israel y la consolación del individuo". Teologia del Antiguo Testamento. I. Teología de las tradiciones hisióricas de Israel, Salamenca, 1969, pp. 469-508; Idem, "Causas y cfectos. Relación entre conducta y retribución". Sabiduria de Israel. Madrid, 1985, pp. 158-173. 
los años 609 a 500 a. C. ocurte la persecución histớrica de personas justas y de profetas, la muerte violenta e inesperada del buen rey Josias, la muerte del pueblo inocente a manos de los ejércitos de Nabucodonosor, el exilio en Babilonia y el sufrimiento del pueblo para poder regresar a la tierra. La doctrina de la relribución entra en crisis.

\subsection{Las grandes preguntas que se hace Israel}

En ese conlexio surgen las grandes preguntas para la le de Israel: ise debe aceptar, simplemente, el sufrimiento y el mal sin preguntarse sobre la realidad e, incluso, sobre Dios? Más en concreto, ¿tiene o no tiene poder Dios? ¿Es indiferente ante lo que le ocurre a su pueblo? ¿Es Dios el origen del sufrimiento y del mal para el creyente, o porque es injusto, o porque le quiere probar caprichosamente, o porque le castiga inmisericordemente, o porque deja de ser fiel y rompe la alianza con El? Dicho de modo radical, ¿tiene sentido seguir hablando de Dios desde la experiencia del sufrimiento y del mal? Pero también, dicho ahora paradojicemente, ¿no se podrá hablar más auténuicamente de Dios, precisamente desde esta experiencia? En defínitiva, ¿dónde se encuentra Dios, sobre todo cuando el pueblo o la persona inocente sufre y es victima del mal?'.

Estas preguntas que se hacía el pueblo de Dios, siguen siendo universales y actuales, por qué los más inocentes siguen sufriendo, por que sufren, a causa de la naturaleza y, o de las personas injustas, por qué aumenta cada día más el sufrimiento de los inocentes y empobrecidos del tercer y cuarto mundo, por qué aumenta sin cesar el placer y la buena vida de los desaprensivos y enriquecidos.

\subsection{Algunas respuestas no convincentes}

Ante esto se siguen dando muchas respuestas ${ }^{6}$, a las cuales ya hemos alusión, que no acaban de convencer, ni a la razón, ni al corazón, ni a la fe. Recordemos algunas de ellas y las preguntas que dejan sin responder. "El grupo y el colectivo es to más importante"; pero entonces idónde quedan el individuo y la persona? "La retribución corporaliva o familiar lo explica codo"; pero inada importa la responsabilidad personal? "Dios retribuye individualmente, premiando o castigando, según sean los actos de cada persona"; pero «cómo explicar el sufrimiento de antos inocentes y empobrecidos quienes según esta respuesta aparecerfan como malditos de Dios? "El sufrimiento es una prueba de Dios": pero ¿no sería esto una muestra de un Dios caprichoso? "Dios finalmente im-

5. Rafael de Sivane, Lo sabidurfa de Israel. ¿Conformismo o liberación?, San Salvador, 1992, pp. 29-32; Dios camina con los pobres, San Salvador, 24 ed., 2000, pp. 141-142.

6. Rafael de Sivante, La sabidurta de Israel. ¿Conformismo o liberacion?. San Salvador, 1992, pp. 29-32. 
plantará la juslicia": pero ¿y si no se cree en el más allá, como era el caso entre la mayoría de los grandes creyentes del Antiguo Testamento? "A pesar de lodo, a pesar de no ver claro, se tiene que seguir con fe y confianza"; pero ino puede resultar esta postura algo alienante? "La relación con Dios es tan fuerte que seguirá a través del sufrimiento y del mal, e incluso después de la muerte". Esta es la última respuesta de fe dada por los creyentes del Antiguo Testamento, aunque para llegar a ella haya sido necesario un largo y crítico camino para no caer en simplismos o alienaciones de ningún tipo y para mantenerse en el equilibrio y la integración de las que llamamos "esta" y "la otra" vida".

\subsection{Conclusión}

En conclusión, se puede afimar que los creyentes del Antiguo Testamento hicieron con hondura la experiencia del sufrimiento y del mal, sobre todo de los inoeentes. Y como todos los seres humanos fueron buscando respuestas para poder llegar a vivir con un cierto sentido, y las fueron encontrando, a partir de su experiencia de fe. Las respuestas fueron variadas, y todo ello desembocó en la última palabra, la del sufrimiento solidario y vivificador de Jesús en la cruz. así como la de tantos testigos o mártires, a lo largo de la historia.

A continuación me voy a centrar en el Antiguo Testamento. especialmente en la tradición profética y sapiencial, dejando de lado las numerosas reflexiones de las plegarias de los salmos. En concreto, en esta primera parte, voy a fijarme en las confesiones de Jeremías, el diálogo de Habacuc con Dios y los cánticos del Siervo sufriente de Yahveh, dejando para una segunda parte el libro de Job y las reflexiones del libro de la Sabiduría sobre la persecución de los justos, por parte de los injustos. De todos estos libros, expondré los textos más relevantes para el tema.

\section{Los profetes}

\subsection{Jeremias y sus confesiones}

Comencemos por Jeremfas y sus confesiones. Es bien conocido que Jeremías fue un profeta que vivio muchas situaciones de contradicción, tanto externa

7. Luc H. Grollenberg. "La esperanza de vida etema", Visión nueva de la Biblia, BarceIong, 1972 pp. 289-293.

8. Wilhelm Rudolph, Jeremia, Handbuch zum Alten Tesiament, 12, J. C. B. Mohr (Paul Siebeck). Tübingen, 3" ed., 1968; Gerhard von Rad, "Jeremlas", Teología del Antigno Testamenio. II. Teologia de las tradiciones proféricas de IsraeL Salamanca, 1969. pp. 239-274; Idem, "Las confesiones de Jeremuas", Estudios sobre el Anriguo Testamen10, Salamanca, 1976, pp. 461-471; L. Alonso Schökel y J. L. Sicre Diaz, "Jeremfas", Profetas. Comentario. I, Madrid, 1980, pp. 399-653: José Luis Sicre, Profetismo en Israel. Estella, 1992; Jacques Briend, El libro de Jeremias, Cuademos Bíblicos, 40. Estella, 2a. ed.. 1984; Carlos Mesters, El profeta Jeremías. Boca de Dios, boca del 
como interna. Por lo que toca a la explicación del sufrimiento, por un lado fue gran defensor de la responsabilidad personal, de acuerdo a lo cual las personas que han vivido según la voluntad de Dios, siéndole obedientes y fieles en todas sus acciones, están llamadas a la felicidad. Pero, por otro lado, también fue testigo de cómo el sufrimiento, el mal y la muerte se cebaban en muchos inocentes, comenzando por el buen rey Josias, pasando por las victimas del opresor rey Joaquín I y por los sufrimientos que él mismo padeció en persona, por sus fuertes denuncias contra Jogquín I y sus colaboradores más cercanos.

Las persecuciones que sufrí de parte de Joaquin I, comenzaron el año 609 y fueron tan fuertes que, en varias ocasiones, estuvieron a punto de llevarle a la muerte. Este hecho y la conciencia de que todo ello le ocurría por ser fiel a Dios y por pronunciar su palabra, en aquellas situaciones concretas, lo llevaron a grandes crisis, que afectaron incluso su fe en Dios. Dichas crisis han quedado recogidas en las llamadas Confesiones de Jereiniar. En ellas encontramos elementos importantes de la postura que adopla este gran creyente frente al sufrimiento y el mal. De sus cinco confesiones, conservadas en el libro de Jeremlas, voy a comentar sólo las tres más completas.

Antes de empezar, hay que recalcar que todas las confesiones tienen un mismo esquema literario, el del género de lamentación o súplica, hecha ante el sacerdote del santuario - pero dirigida a Dios-, por una grave necesidad, que se está viviendo. Tales lamentaciones y súplicas solfan terminar con una palabra tranquilizadora de parte de Dios, por medio del sacerdote. Como veremos, una de las grandes originalidades de Jeremías consistió en usar ese género literario. pero transformándolo profundamente de la siguiente manera. En primer lugar, la súplica de Jeremías no se hace en el templo, ni en presencia del sacerdote, sino que la hace en cualquier lugar y momento de la vida y va dirigida directamente a Dios. En segundo lugar, la respuesta no es tranquilizadora y consoladora, y no la recibe por medio del sacerdote, sino que Dios mismo le responde, y lo hace de modo intranquilizador, provocador, interpelante.

Según esto, las partes en que se divide cada confesión son las siguientes: Jeremías presenta el sufrimiento que le produce la persecución de que es objeto; formula la gran crisis que está viviendo, en su misión y en su fe, que lo lleva a dudar incluso de Dios; suplica a Dios que se ponga de su lado y lo defienda de sus perseguidores atacándolos; escucha la respuesta-reto de Dios y es interpelado a seguir lleno de confianza y comprometido con la causa, a pesar de la inseguridad y los peligros que le esperan. Veamos, ahora, la primera de las confesiones.

pueblo, Bogota, 1994: Carlos Junco Garz, "La experiencia profética en las confesiones", Palabras sin fronteras. Los profetas de Israel, México, 2000, pp. 443-454. 


\section{Jeremías 11, 18 - 12, 6}

Jeremias comienza la confesión reconociendo que ha sido Dios quien le ha dado a conocer lo que su familia está maquinando contra él, sin que êl, inocente, se entere. Lo que maquinan no es otra cosa que su destrucción (Jeremías 11, 18; $12,6 ; 11,19)$.

Yahveh me lo hizo saber, y me entert de ello. Tú, Yahveh, me descubriste sus maquinaciones: "Porque incluso tus hermanos y la casa de tu padre, ésos también te traicionarán y a tus espaldas gritarán. No te fíes de ellos, cuando te digan hermosas palabras". Y yo que estaba como cordero manso llevado al matadero, sin saber que contra mí tramaban las siguientes maquinaciones: "destruyamos el árbol en su vigor; borremoslo de la tierra de los vivos y no vuelva a mencionarse su nombre".

La razón de esta maquinación familiar es posiblemente el hecho de que el padre de Jeremías, debido a la reforma del rey Josías y la ley de centralización del culto, en Jerusalen, ha pasado a ser sacerdote del Templo de Jensalen. Y eso ocurre, precisamente, cuando Jeremías denuncia con fuerza la hipocres/a de quienes van a dar culto a Yahveh, en el templo. Es evidente que la postura de Jeremías no ayudaba en nada al buen nombre de su padre y de su familia

El descubrimiento de esta maquinación lleva al profeta a dirigirse al Señor. Ya que él conoce lodo, conoce también el interior del profeta y cómo su corazón está con El. Le pide, en consecuencia, que haga justicia contra los malvados que lo persiguen, ya que Jeremías ha puesto su causa en las manos de Dios (Jeremias $11,20 \mathrm{a} ; 12,3 ; 11,20 \mathrm{~b})$. Dice a Yahveh:

¡Oh Yahveh Sebaot, juez de lo justo, que escrulas los riñones y el corazón! Tú me conoces, Yahveh; me has visto y has comprobado que mi corazon está contigo. Llévatelos como ovejas al matadero y conságralos para el día de la matanza; vea yo tu venganza contra ellos, porque a ti he manifestado mi causa.

El profeta, entonces, escucha la repuesta de Dios, aparentemente tranquilizadora, ya que le promete acabar con sus perseguidores, ;con su propia familia! (Jeremias 11, 21-23).

En efecto, asi dice Yahveh sobre los de Anatot, que buscan mi muerte diciendo: "No profetices en nombre de Yahveh, y no morirás a nuestras manos". Por eso, asi dice Yabveh Sebaot: "He aqui que yo los voy a visitar. Sus jóvenes morirán por la espada, sus hijos e hijas morirán de hambre, y no quedará de ellos ni reliquia, cuando yo traiga la desgracia a los de Anatot, el año en que sean visitados".

Pero, como era de suponer, esto no tranquiliza a Jeremías, ya que es persona con gran sentido familiar, que no desea en absoluto la muerte de su familia. 
Jeremías, en consecuencia, saliendose de su caso particular y planteándose el problema más general del sufrimiento y del mal que caen sobre los más inocentes y justos, increpa a Dios, a pesar de que sabe que saldrá perdiendo, en la discusión con el. Le hace la gran pregunta de por que los perversos. los que producen sufrimiento a su alrededor prosperan, a pesar de que son falsos cuando hablan de Dios, ya que, en realidad, no quieren saber nada de él (Jeremias 12, I2.4b).

Tú llevas la razón. Yahveh. cuando discuto contigo. No obstante, voy a tratar contigo un punto de justicia. ¿Por qué tienen suente los malvados, y son felices todos los perversos? Los plantas y enseguida arraigan, van a más y dan fruto. Es verdad que tú estás siempre en sus bocas, pero no en su corazón (sus riñones)... Porque andan diciendo: "No ve Dios nuestros senderos".

Para colmo, su acción injusta repercute hasta en la naturaleza. La pregunta es entonces hasta dónde permitirá Dios que lleguen las cosas (Jeremías 12, 4a).

¿Hasta cuándo estará de luto la tierra y la hierba de todo el campo estará seca?

Por la maldad de los que moran en ella han desaparecido bestias y aves.

Dios responde a Jeremáas, no le ofrece tranquilidad, sino que lo desaffa y lo provoca, y le anuncia que aún le van a acontecer cosas peores; que se prepare. pues, a seguir y que no busque seguridades (Jeremias 12,5). Le dice:

Si con los de a pie corriste y te cansaron, icómo competirás con los de a caballo? Y si en tierra abierta te sientes inseguro, ¿qué harás cuando te encuentres en medio de los bosques del Jordán?

Esta primera confesión de Jeremías expresa, pues, el profundo sufrimiento del profeta, a causa de la persecución, de parte de su propia familia y a causa también de la solución que Dios le ofrece: la destrucción de sus familiares, que lo persiguen. Y sobre todo, el sufrimiento ante el problema más global: la experiencia de que a los injustos las cosas les van bien y a los inocentes les van mal.

La actitud y respuesta de Dios ante el sufrimiento de Jeremfas es doble. Dios no quiere que el profeta sea perseguido, ni que los opresores e injustos maltraten a los inocentes, ni que provoquen con sus acciones un desastre ecológico. Es decir, Dios no está a favor del mal y del sufrimiento, lo cual se mantiene como afimación fundamental al tratar el problema del mal. Pero al mismo tiempo. Dios exige al profeta que siga adelante, amn en medio del sufrimiento y del mal, y que trabaje con todas sus fuerzas para que vaya desapareciendo el mal y el sufrimiento del mundo.

\section{Jeremins 15, 10-21}

En esta segunda confesión, las quejas de Jeremías suben de tono. Se queja de haber nacido, pues todos lo están maldiciendo, sin que él haya dado motivo para 
ello. Entonces le pregunta a Dios si no ha ohedecido las órdenes que le ha ido dando (Jeremias 15, 10-11).

¡Ay de mi, madre mia. porque me diste a luz, varón disculido y debatido por Indo el pais! Ni les deho. ni me Jchen. ipero Indos me maldicen! Di. Yahveh, si no te he servido bien: intercedi anle li por mis enemigos en el liempo de su mal y de su apuro.

Dios le da una primera respuesta y le exige mantenerse firme ante las persecuciones y resistir como acero y bronce, ya que Dios ha hecho a Jeremias acero y hronce (" $j$, Se mella el acero, el acero del norte, y el hronce?". Jeremias 15, 12).

Pero Jeremias vuelve a insistlir. y ahora le pide a Dins que no se olvide de él. que le haga juslicia conlra sus perseguidores, que lenga en cuenla que la persecución le sohreviene por serle fiel a cl y a su palahra. Y le pide a Dios que recuerde que él. Jeremias. en medio de la persecución. ha lenido que manienerse solo. precisamenle, para expresar de forma simbólica el enojo de Dios conlra su puehlo (Jeremias 15, 1.5-17).

Tú lo sahes. Yahveh, acuérdate de mi, visítame y véngame de mis perseguidores. No dejes que por alargarse iu ira sea yo arrehatado. Sábelo: he soporlado por ti el oprobio. Se presenlaban tus palabras, y yo las devoraba; era tu palabra para mi un gozo y alcgria de corazón, porque se me llamaba por lu Nombre Yahveh, Dios Sebaot. No me senlé en peña de gente alegre y me holgué: por obra luya, solitario me senté, porque de rabia me llenasie.

Jeremias acaba pregunlando por qué Dios permite que se prolongue esila siluación. y con palabras fuentes llega a recriminarlo. porque es una fuente engañosil. un espejismo en el desieno (Jeremias 15, 18).

¿Por qué ha resulıado mi penar perpeluo. y mi herida imemediable, rehclde a la mcdicina? ;Ay! iscrás tú para mi como un espejismo, aguas no verdaderas?

Dios, por lin, responde al profela. Lo rela a que vuelva a Dios, a que sepa discernir lo que realmente è desea y a manienerse fiel, en el servicio de Dios. Pero lambién le promelc que estará a su lado, cuando lo golpcen y lo quieran malar (Jeremias 15, 19-21).

Entonces, Yahveh dijo asi: "si le vuelves porque yo te haga volver, estarás en mi presencia: y si sacas lo precioso de lo vil, serás como mi hoca. Quc cllos se vuelvan a ti, y no tú a ellos. Yo te pondré para este pucblo por muralla de bronce inexpugnable. $Y$ pelearán conligo. pero no ie podrán. pues contigo esioy yo para librante y salvarte $\rightarrow$ oráculo de Yahveh-. Te salvaré de mano de los malos y te rescataré del puño de esos rahiosos".

El mal y el sufrimiento, pues, no van a desaparecer por arte de magia, ni por un aclo maravilloso y milagroso de Dios. Van a seguir acompañando al profela. 
Lo imponante es, sin embargo. la promesa de Dios de darle fuerza para soportarlos y seguir adelante con su misión, a la cual le sigue llamando.

\section{Jeremias 20, 14-18.7-13}

En esta última confesión, Jeremías comienza maldiciendo fortísimamente el dia en que nació y a las personas que se alegraron por ello. Dado el gran mal que padece. desearia no haber visto la luz y quedar sepultado. en el seno de su modre (Jeremias 20, 14-18).

¡Maldito el día en que nacr! ¡El día que me dio a luz mi madre no sea bendito! ¡Maldito aquel que felicitó a mi padre diciendo: 'te ha nacido un hijo varón", y le llenó de alegria! Sea el hombre aquel semejante a las ciudades que destruyo Yahveh sin que le pesara, y escuche alaridos de mañana y gritos de ataque al mediodia. ;Oh, que no me haya hecho morir desde el vientre, y hubiese sido mi madre mi sepultura, con seno prē̄ado eternamente! ¿Para que haber salido del seno, a ver pena y aflicción, y a consumirse en la vergilenza mis dias?

A continuación, Jeremías recrimina a Dios, porque lo ha enganado, lo ha forzado a decir cosas que no le gustan a el, ni tampoco a la gente; y jlo peor es que no puede dejar de decirlas! (Jeremías 20, 7-9).

Me has seducido, Yahveh, y me deje seducir, me has agarrado y me has podido. He sido la irtision cotidiana: todos me remedaban. Pues cada vez que hablo es para clamar: "¡Atropello!", y para gritar: "¡Expolio". La palabra de Yahveh ha sido para ml oprobio y befa cotidiana. Yo decla: "No volvere a recordarlo, ni hablaré más en su Nombre". Pero habla en mi corazón algo asi como fuego ardiente, prendido en mis huesos, y aunque yo trabajada por abogarlo, no podia.

Comparte, entonces, con Dios la experiencia de sentirse perseguido por la mayoría e incluso por los amigos, que s6́lo estan esperando que tropiece y caiga. Esto le duele profundamente (Jerem(as 20, 10).

Escuchaba las calumnias de la turba: " $i$ Terror por doquier!, ¡denúncienle!, ¡denunciémosie!". Todos aquellos con quienes me saludaba estaban acechando un traspiés mio: " $i A$ ver si se distrae, y le podremos, y tomaremos venganza de $t ! ! "$.

Llegando al punto culminante de la crisis, el profela suplica a Dios que actúe en su favor, ya que él conoce las profundidades del ser humano. y por tanto, lo que Jeremias piensa y siente. Hace esta súplica desde la confianza, nacida de la experiencia de sentir a Dios a su lado, un Dios que se preocupara del profeta y lo cuidará contra los perseguidores (Jeremías 20, 12.11). 
¡Oh Yahveh Sebaot. juez de lo justo, que escrutas los riñones y el corazón!, vea yo tu venganza contro ellos, porque a ti he encomendado mi causa". Pero Yahveh está conmigo, cual caropeón poderoso. $Y$ así mis perseguidores tropezarán impotentes; se avergonzarán mucho de su imprudencia: confusión eterna, inolvidable.

El profeta acaba con un cántico de acción de gracies, porque Dios. en último têrmino, salva la vida de los pobres (Jeremias 20,13).

Canten a Yahveh. alaben a Yahveh. porque ha salvado la vida de un pobrecillo de manos de malhechores.

Una vez más, el mal y el sufrimiento llevan a Jeremias hasta el límite de lo que una persona, y sobre todo una persone de su sensibilidad, puede soportar. EI profeta desea la muerte o que Dios se ponga claramente de su lado, frente a aquellos que lo maltratan y hacen sufrir. Dios le da a entender que él no está de acuerdo, ni se conforma con el mal y el sufrimiento y lo Lama a no conformarse tampoco él y a luchar por vencerlos. Pero, en definitiva, la respuesta no es otra que la de provocar en el profeta la confianza y la seguridad de que. en último término. Dios no lo va a abandonar, sino que va a estar a su lado, como está al lado de quienes sufren, por causa del mal y, sobre todo. de su lucha contra el mal y el sufrimiento, en el mundo.

\subsection{El dislogo de Habacuc con Dios'}

Contemporáneo, al menos en parte. de Jeremias vive el mismo contexto histórico y la misma problemática que él. No puede entender tampoco cómo Dios permite que en la historia vayan tan mal las cosas, cómo las personas injustas y prepotentes triunfan en la vida, mientras los inocentes y sencillos sólo encuentran obstáculos para poder vivir y sobrevivir. En consecuencia, dialoga muy apasionadamente y con gran tensión con Dios, de un modo parecido a como hemos visto que lo hacia Jeremías.

Habecuc 1, $2-2,4$

33 En este texto aparece un doble diálogo de Habacuc con Dios. Protestará por primera vez, y, ante la respuesta que Dios le da, volverá a protestar con muche más fuerza. Entonces, Dios le dará una respuesta, que no tiene apelación.

9. Gerhard von Rad, "El paso a la Epoca babilónica (Nahum, Habacuc, Sotonlas)". Teologia del Antiguo Tesiamenio. II. Teología de las iradiciones proféticas de Israel. Salamanca, 1969. pp. 235-239; L. Alonso Shokel y J. L. Siere Diez, "Habscuc". Proferas. Comentorio, 1. Medrid, 1980. pp. 1091-1108; Jose Luis Sicre, Proferismo en Isroel. Estella. 1992: Corlos Junco Garza, "Los imperios en Nahum. Habecuc y otros profetas", Palabra sin fronteras. Los profetas de Israel, México, 2000. pp. 400 . 424. 
La primera protesta (Habacuc I. 2-4) parece hacer referencia a las víctimas que produce la persecución de Joaquín l (609-598). La injusticia y la violencia crecen.

¿Hasta cuándo, Yahveh, pedire auxilio. sin que tú escuches, clamaré a ti: "¡Violencia!" sin que tú salves? ¿Por que me haces ver la iniquidad, mientras tú miras la opresión? iAnte mí hay rapiña y violencia, se suscitan querellas y discordias! Pues la ley se desvirtúa, no se hace justicia. ¡El impio asedia al justo, por eso se pervierte la justicia!

Dios le responde (Habacuc 1,5-11) que él pone en pie de guerra a los caldeos para que invadan Juds y acaben con la injusticia del rey opresor Joaquín l. En la respuesta el mismo Dios reconoce que es bien conocido de todos el espiritu violento y agresivo de los caldeos. $Y$ acepta que su respuesta no llena demasiado las expectativas de los reclamos de Habacue.

Miren a las naciones, contemplen, queden estupefactos, atónitos: voy a hacer una obra en sus dfas que no creerían si se la contasen. Pienso movilizar a los caldeos, un pueblo cruel y fogoso, que reconre las anchuras de la tierra, para adueriarse de parses ajenos. Es terrible y espantoso, impone su ley y su poder; son más raudos que panteras sus caballos, más ágiles que lobos esteparios. Sus jinetes galopan, vienen de lejos sus jinetes, vuelan como águila que se lanza a devorar. Llegan todos para hacer violencia, son sus rostros ardientes, como un viento del este, amontonan cautivos como arena. Se burla de los reyes, los soberanos le sirven de irrisión; se rie de toda fortaleza. levanta un terraplén y la toma. Después cambia el viento y desaparece, culpable por hacer de su fuerza su dios.

Por el mismo espiritu violento y agresivo de los caldeos, Habacue ve que la solución que Dios propone será más problemática de lo que él planteaba. Ve que los invasores harán más daño, ya que. además, ellos dan culto al poder. Se pone, entonces, a la expectativa para ver qué le responde Dios (Habacuc 1, 12-2,1).

¿No eres tú desde antiguo. Yahveh, mi Dios, mi santo? ¡Tú no mueres! ¡Para juzgar lo pusiste, Yahveh, oh Roca, fiscal lo nombraste! Tus ojos puros no pueden ver el mal, eres incapaz de contemplar la opresión. ¿Por qué ves a los traidores y callas cuando traga el impío al que es más justo que el? Tratas a los hombres como a peces del mar, como a reptiles que no tienen amo. A todos los pesca con anzuelo, los apresa en su red, los recoge en su copo. Por eso se alegra y regocija, por eso sacrifica a su red y ofrece incienso a su copo, pues por ellos abunda su presa, su comida es suculenta. Por eso vacla su red sin cesar, matando naciones sin piedad. Mi puesto de guardia ocuparé. arriba en la muralla me pondre, oteando para ver lo que me dice, lo que responde a mi querella. 
Dios responde al profeca y le dice que escriba la respuesta. ya que de momento no se realizará lo que Dios dice. pero al final, sf se hará realidad. La sentencia es que el orgulloso y opresor fracasará; los justos e inocentes, en cambio. finalmente, triunfarán y se reirán de aquéllos. Estas burlas aparecen en forma de cinco maldiciones o lamentaciones (Habacuc 2, 2-6a; véase 2, 6b-20).

Yahveh me respondió de este modo: "Escribe la visión, ponla clara en tablillas para que pueda leerse de corrido. Porque tiene su focha la visión, aspira a la meta y no defrauda; si se atrasa, espérala, pues vendrá cieramenle, sin retraso. Sucumbirá quien no tiene el alma recta, mas el justo por su fidelidad vivira".

En definitiva, el mal y el sufrimiento externo e interno vividos por Habacuc son tan grandes que no puede dejar de protestar ante Dios, ya que no entiende su manera de llevar la historia. La respuesta de Dios vuelve a ser parecida a la dada a Jeremías. Sólo el mirar con ojos de le la profundidad de la historia hará posible ver en ésta la presencia oculta y misteriosa de él. Dios vuelve a pedir al profeta que siga firme en su inocencia y su justicia, las cuales se convertirán en la base y fundamento de su confianza y de su vida.

\section{Los cánticos del Siervo de Yabveh"}

Después de las protestas de Jeremías y Habacuc, y de las respuestas intranquilizadoras y provocadoras de Dios, tuvo lugar la invasión del imperio babilonio (598), la destrucción de la ciudad y del Templo de Jerusalén (587), y la deportación de judjos a tierras babilonias (la primera de las cuales comenzó en 598).

En Babilonia (598-538), los judlos viven una gran crisis de confianza en Dios y en si mismos. Muchos creyentes, sin embargo, los acompañan y los animan. dándoles motivos de esperanza. Entre estos creyentes están los disclpulos del antiguo profeta Isaías, los que suelen ser llamados con el nombre genérico de Segundo Isáas o Deutero Isalas.

Estos hablan de un Dios que sigue siendo Señor y Soberano de la historia de su pueblo, que se compadece de éste en el exilio, que provocará y conducirf el

10. Gerhard von Rad, "El nuevo siervo de Yahveh", Teología del Antiguo Tesiamento. II. Teologla de las tradiciones proféricas de Israel, Salamanca, 1969, pp. 314-325: L. Alonso Schókel y J. L. Sicre Diaz, "Isalas II", Profetas. Comentario. I, Madrid, 1980. pp. 263-340; José Luis Sicte, "Los cantos del Siervo de Yahveh", Los proferas de Israel y su mensaje. Antologia de textos, Madrid, 1986, pp. 239-247; Profetismo en Israel, Estella, 1992; Claude Wiéner. El segundo Isalas. El profeta del nuevo drodo. Cuademos Bíblicos, 20, Estella, 4a. ed., 1985; Carlos Mesters, La misión del pueblo que sufre, Madrid, 1983; Carlos Junco Garza, "El Siervo de Yahvé en el Deutero Isaias (Is 40-55)". Palabra sin fronseras. Los profelas de Israel. México, 2000, pp. 620-643. 
retorno hacia la tierra por medio del desierto. y que reconstruirá y renovará a su pueblo, en Judá. Pero el dolor del pueblo en el exilio y la conciencia del sufrimiento que tendrán que soportar para conseguir el regreso a la tierra y la reconstrucción del país hacen que el profeta se plantee qué hará Dios, en esas circunstancias. Dado el continuo acercamiento de Dios al pueblo y la conciencia de que él está cada vez más presente en su bistoria, el Segundo Isaías llega a preguntarse, por primera vez, si el mismo Dios sufrirá y soportará el mal solidariamente con el pueblo. El problema que esto plantea es obvio: la fe de Israel, según todo lo que sabemos, no podia llegar, en aquel momento, a hacer este tipo de afimación, pues se vendría a decir que Dios puede sufrir. Esto ina contra la convicción, tantas veces afimada tambien por el Segundo Isaias y por otros creyentes contemporáneos, de que Dios es creador, poderoso y señor de la historia, y que, por tanto, no puede sufrir, ni ser victima del mal. Sin embargo, el Segundo Isaías se lo plantea, y lo hace, probablemente, a partir de la experiencia de profetas como Jeremías y de la suya propia. Llega a captar que personas intimamente unidas a Dios se unen de tal manera al pueblo sufriente que, ellas mismas, sufren, acompañandolo y mostrando así, de alguna manera, que Dios está cerca de dicho pueblo.

Es entonces cuando comienza a hablar de la figura del Siervo sufriente de Yahveh, que se convierte en una figura mediadora de la solidaridad de Yahveh con el pueblo sufriente. Desarrolla esta imagen en los cuatro cánticos del Siervo: Isaras 42, 1-9; 49, 1-6; 50,4-9;52, $13-53,12$. Donde aparece con mayor fuerza el sufrimiento solidario del Siervo es en Isaías 52, 13 - 53, 12; pero es importante tener en cuenta los otros tres textos para poder captar, de algún modo, el desarrollo y la riqueza de dicho personaje, y sobre todo su identificación y unión íntima con Dios. Veámosio.

\section{Isaias 42, 1-9}

En este primer cántico, Dios presenta a su Siervo, el elegido, en quien se ha complacido. Lo presenta también como el ungido por Dios, enviado para cumplir su mision nacional y universal de llevar la justicia y animar a quienes decaen (Isafas 42, 1-4)

He aqur mi siervo a quien yo sostengo, mi elegido en quien se complace mi alma. He puesto mi espíritu sobre él: dictará ley a las naciones. No vociferará, ni alzará el tono, y no herá oír en la calle su voz. Caña quebrada no partifa, y mecha mortecina no apagara. Lealmente hara justicia; no desmayará, ai se quebrará hasta implantar en la tierra el derecho, y su instrucción atenderán las islas.

Ese Dios, como creador de todo, como todopoderoso y donador de vida, se dirige después al Siervo y le hace ver que el lo ha llamado, le ha mostrado su benevolencia, lo ha tratado Intimamente, le ha dado la misión de ser alianza y 
luz de los pueblos y de hacer recobrar la vista a los ciegos. de hacer salir a los cautivos de la cárcel, de sacar del calabozo a los que estaban en las tinieblas. Su misión tiene que ver, pues, con el mal que padecen los que sufien (Isalas 42, 5.7).

Así dice el Dios Yahveh, el que crea los cielos y los extiende, el que hace furme la tierra y lo que en ella brota, el que da aliento al pueblo que hay en ella, y espiritu a los que por ella andan: "Yo, Yahveh, te he llamado en justicia, te asI de la mano, te formt, y te he destinado a ser alianza del pueblo y luz de las gentes, para abrir los ojos ciegos, para sacar del calabozo al preso, de la cárcel a los que viven en tinieblas.

Dios acaba afirmando que él mismo, por medio de su Siervo, hará toda esta novedad. Dios, pues, se declara totalmente identificado con su Siervo y con la misión que le ha dado. Por tanto, lo que haga el Siervo lo hace Dios. Y éste es un tema decisivo para iluminar el terna, que estoy tratando (Isaras 42, 8-9).

Yo, Yahveh, ése es mi nombre, mi gloria a ouro no cedo, ni mi prez a los idolos. Las cosas de antes vean que vinieron. Otras nuevas yo les anuncio: antes de que broten se las hago ofr.

Sin duda, uno de los aspectos más importantes, en este primer cántico, es la misión que recibe el Siervo de cara a los que sufren y la total identificación que se da entre Dios mismo y este Siervo.

\section{Isaías 49, 1-11}

En el segundo cántico, el Siervo transmite a todos su experiencia de vocación, de preparación para la misión. de prolección y de definición como Siervo (Isalas 49, 1-3).

¡Oidme, islas, atended, pueblos lejanos! Yahveh desde el seno matemo me llamb; desde las entrañas de mi madre recordó mi nombre. Hizo mi boca como espada afilada, en la sombra de su mano me escondi6; hizome como saera aguda, en su carcaj me guard6. Me dijo: "Tú etes mi siervo (Israel), en quien me gloriare".

El Siervo transmite también sus dudas y la sensación de fracaso, pero al mismo tiempo la certeza de que está en manos de Dios y de que la misión que tiene le está dada por el mismo Dios, el cual lo envía como Siervo con dos grandes funciones: la de volver a dar vida a Israel y la de llevar la salvación a toda la tierra (Isajas 49, 4-11).

Pues yo decla: "Por poco me he fatigado, en vano e inútilmente mi vigor he gastado. ¿De veras que Yahveh se ocupa de mi causa, y mi Dios de mi trabajo?". Ahora, pues, dice Yahveh, el que me plasmb desde el seno materno para siervo suyo... "Poco es que seas mi siervo, en orden a levantar las tribus de Jacob, y de hacer volver los preservados de Israel. Te voy a poner 
por luz de las gentes, para que mi salvación alcance hasta los confines de la tierra". Así dice Yahveh, el que rescata a Israel, al eselavo de los dominadores: "En tiempo favorable te escuchare, y en día nefasto te asistire. Yo te forme y te he destinado a ser alianza del pueblo, para levantar la tierra, para repartir las heredades desoladas, para decir a los presos: 'Salgan', y a los que están en tinieblas: 'Muéstrense'... Convertiré todos mis montes en caminos. y mis calzadas serán levantadas".

Así, pues, en este canto se expresa de nuevo una fuerte unión íntima e identificación del Siervo con Dios, que lo hace tener confianza, en medio de las dudas y fracasos, y lo lleva a cumplir sus proyectos liberadores, acompañando solidariamente al pueblo sufriente. De este modo, el dolor del pueblo le llega a tocar a Dios y la solidaridad de Dios con el pueblo sufriente le liega a éste por medio del Siervo.

\section{Isajas 50, 4-9}

En el tercer cántico, el Siervo habla de nuevo. Afirma que dice y hace aquello que Dios le ha enseñado y le ha ordenado. Lo hace con total obediencia (Isaías 50, 4-5a).

El Señor Yahveh me ha dado lengua dócil, que sabe decir al cansado palabras de aliento. Temprano, temprano despierta mi of́do para escuchar, igual que los discípulos. El Señor Yahvéh me ha abierno el oído.

A pesar de las persecuciones que ha soportado, el Siervo dice que las ha resistido, porque sabe que el Señor está a su lado y además, lo más importante, lo esı́́ declarando inocente y se ha constituido en su defensor. Esıı hará caer a sus perseguidores (lsaías 50, 5b-10).

Y yo no me resisti, ni me hice aurás. Ofrecí mis espaldas a los que me golpeaban, mis mejillas a los que mesaban mi barba. Mi rostro no huré a los insultos y salivazos. Pues que Yahveh babria de ayudarme ..., por eso puse mi cara como el pedemal, a sabiendas de que no quedaría avergonzado. Cerca está el que me justifica: ¿quién disputara conmigo? ... He aqul que el Señor Yahveh me ayuda: ¿quién me condenará? Pues todos ellos como un vestido se gastarán ... El que de entre ustedes tema a Yahveh, oiga la voz de su Siervo. El que anda a oscuras ... confle en el nombre de Yahveh y apóyese en su Dios.

Una vez más aparece el tema de la identificación y la unión íntima entre el Siervo y Dios. Esto es lo que hace que el Siervo se mantenga firme y confiado en medio de las persecuciones y dificultades; tiene la certeza de que Dios está junto a él que sufre, como él debe estar junto al pueblo que sufre, realizando la misión liberadora y consoladora, que Dios mismo le ha encomendado. 


\section{Isafas 52,13 - 53,12}

El último cántico del Siervo es el que más puede iluminar el tema que estoy tratando, aunque, como decía antes, presupone los tres cánticos anteriores y sus grandes afimaciones.

Habla, en primer lugar, Dios y presenta el futuro glorioso de su Siervo. Un futuro, sin embargo, al que llegará después de haber pasado por una situación en la que ni mostraba apariencia humana. De esta manera, por contraste, iniciará el camino de la humanización, en provecho de todos los pueblos (Isaías 52, 13-15).

He aquí que prosperará mi Siervo, será enaltecido, levantado y ensalzado sobremanera. Así como se asombraron de él muchos — pues tan desfigurado tenía el aspecto que no parecia hombre, ni su apariencia era humana-, otro tanto se admirarán muchas naciones; ante él cerrarán los reyes la boca, pues lo que nunca se les contó verán, y lo que nunca oyeron reconocerán.

Habla a continuación el pueblo, el cual describe la realidad del sufrimiento del Siervo, tan grande que ni se atrevia a mirarlo; el mismo pueblo lo despreciaba como a maldito de Dios. Finalmente, el pueblo reconoce que el Siervo sufría solidariamente, porque él habla lomado todas las culpas y sufrimientos de toda la humanidad (Isaías 53, 1-6).

¿Quién dio crédito a nuestra noticia? Y el brazo de Yahveh, $i^{a}$ quién se le revel6? Crecí́ como un retoño delante de él, como raíz de tierra árida. No tenía apariencia, ni presencia: (le vimos) y no tenfa aspecto que pudiesemos eslimar. Despreciado, marginado, hombre doliente y enfermizo, como de taparse el rostro por no verle. Despreciable, un Don Nadic. ¡ $Y$ con todo eran nuestras dolencias las que él llevaba y nuestros dolores los que soportaba! Nosotros le tuvimos por azotado, herido de Dios y humillado. El ha sido herido por nuestras rebeldias, molido por nuestras culpas. El soportó el castigo que nos trae la paz, y con sus cardenales hemos sido curados. Todos nosotros como ovejas erramos, cada uno marchó por su camino, y Yahveh descargó sobre él la culpa de lodos nosotros.

El profeta narra, a continuación, cómo vivió el Siervo los sufrimientos: maltratado, humillado, apresado, condenado, muerto, sepultado entre los malhechores. Y sin embargo, a pesar de que no se lo merecia, no obraba con violencia, ni era falso; de hecho, sufria por y en lugar del pueblo. El profela, finalmente, anuncia la vida. la descendencia del Siervo y el Exito del plan salvador del Señor (Lsaías 53,7-10).

Fue oprimido, y él se humillo y no abrí la boca. Como un cordero al degliello era llevado, y como oveja que ante los que la trasquilan está muda. tampoco él abrí́ la boca. Tras arresto y juicio fue arrebatado, y de sus contemporáneos, ¿quién se preocupa? Fue arrancado de la tierra de los vi- 
vos; por las rebeldias de su pueblo ha sido herido; y se puso su sepultura entre los malvados y con los ricos su tumba, por más que no hizo atropello. a hubo engaño en su boca. Mas plugo a Yahveh quebrantarle con dolencias. Si se da a si mismo en expiación, verá descendeneia, alargará sus días, y lo que plazea a Yahveh se cumplirá por su mano.

Habla, finalmente, el Señor acerca de su Siervo y anuncia que tomando las culpas de los demás los ha hecho justos, siendo él justo y sufriente. Por esto, Dios lo ha constituido en Señor de todos, porque ha dado la propia vida hasta la muerte, sufriendo la incomprensión de muchos, que pensaban que él era culpable (Isalas 53, 11-12).

Por las fatigas de su alma, verá luz. se saciara. Por su conocimiento justificará mi Siervo a muchos, y las culpas de ellos el soportara. Por eso le daré su parte entre los grandes y con poderosos repartirá despojos, ya que indefenso se entrego a la muerte y con los rebeldes fue contado, cuando él llevo el pecado de muchos, e intercedió por los rebeldes.

La conclusión es muy imporante. En el conjunto de los cantos del Siervo se habla de la fuerte intimidad del Siervo y Dios. Tanto que se da una identificación. Se recupera también algo de la visión corporativista, aunque sin caer en el fatalismo de que uno sufre por el mal que han hecho otros. En todo caso es una visión corporativista, pero por solidaridad libre y voluntaria. En este sentido, el Siervo, de forma voluntaria, toma sobre el las culpas y sufrimientos de todos, para intentar que éstos no sufran o encuentren acompañamiento en su sufrimiento. Dios sufre, en último término, por medio de su Siervo y acompafia asl a su pueblo sufriente para darle ánimo y ayudarlo a caminar en medio del mal y del sufrimiento, siempre con el horizonte de la eliminación de ese mal y sufrimiento.

\section{Conclusibn}

Recojamos aquí las conclusiones que hemos ido sacando, en cada apartado.

En el caso de Jeremías, vefamos cómo el mal producido por los injusios afecta fuertemente la vida del profeta y lo hace sufrir radicalmente. Este sufrimiento que vive como persona inocente a manos de los injustos lo hace plantear otro problema más profundo como es el por qué los injustos salen siempre bien parados y, en cambio, a los inocentes todo les va mal. Puede parecer que a Dios todo esto le es indiferente, que oo le importa el mal y el sufrimiento, que se ceban sobre los justos $\mathrm{e}$ inocentes.

Dios deja bien claro, sin embargo, que no goza con que Jeremlas sea perseguido, ni con que los injustos opriman y maltraten a los inocentes e incluso provoquen con sus acciones un desastre ecológico. En una palabra. Dios no está a favor del mal y del sufrimiento. Pero al mismo tiempo. Dios reta al profeta a 
seguir adelante. en medio del sufrimiento y del mal, trabajando con todas sus fuerzas para ir haciendo desaparecer el onal y el sufrimiento del mundo.

El mal y el sufrimiento. pues, no van a desaparecer por acto de magia, ni por un acto maravilloso y milagroso de Dios. Van a seguir acompañando al profeta. En muchas ocasiones, además, le van a llevar al límile de desear la muerte. Lo importante es, sin embargo, la promesa de Dios de darle fuerza para soportar el mal y el sufrimiento y para seguir adelante con su misión. Jeremfas, pues, debe confiar y basar su seguridad en el Dios que lo fortalece y lo llama a lucbar contra el mal y el sufrimiento, con los que él no estí de ningún modo conforme.

En el caso de Habacuc. el mal y el sufrimiento externo e interno vividos por él son tan grandes que no puede dejar de protestar ante Dios, ya que no entiende su manera de llevar la historia. En la linea de las respuestas retantes y provocativas que Dios daba a Jeremías, le dice a Habacue que sólo el mirar con ojos de fe la profundidad de la historia hará posible ver en ésta la presencia oculta misteriosa de él. Dios vuelve a pedir al profeta que siga firme en su inocencia y su justicia, las cuales se converiuán en la base y fundamento de su confianza y de su vida, y de la confianza y de la vida del pueblo.

En los cuatro cánticos del Sienvo de Yahveh del Segundo Isaías se va dando un avance progresivo, en lo que se refiere al tema del mal y del sufrimiento. Se anuncia en ellos la misión que recibe el Siervo de cara a los que sufren, sea de donde sean, y se subraya la total identificación que se da entre este Siervo y Dios mismo. Esta total identificacion es la que hace que el Siervo tenga confianza, en medio de las dudas y fracasos, y la que lo lleva a cumplir sus proyectos liberadores, acompañando solidariamente al pueblo sufriente. De este modo, el dolor del pueblo le llega a locar a Dios y la solidaridad de Dios con el pueblo sufriente le llega a éste, por medio del Siervo. Este llega a la certeza de que Dios está junto al que sufre, as! como él mismo debe estar junto al pueblo que sufre.

En el conjunto de los cantos del Siervo, pues, se habla de la honda intimidad del Siervo y Dios. Tanto que se da una identificación. Por esta identificación. el Siervo, libre y voluntariamente, coma encima de el las culpas y sufrimientos de todos, para intentar que éstos no sufran o encuentren acompañamiento, en su sufrimiento. Dios sufre. en último término, por medio de su Siervo y acompaña asl a su pueblo sufriente para darle ánimo y ayudarle a caminar, en medio del mal y del sufrimiento, siempre con el horizonte de la eliminación del $\mathrm{mal} \mathrm{y} \mathrm{del}$ sufrimiento.

El estudio de estos testimonios de tres profetas nos ha llevado a comprender mejor que el mal y el sufrimiento son realidades de nuestra existencia, muchas veces agudizadas por el mal uso que los opresores e injustos hacen de su libertad. Nos ha llevado a comprender, en segundo lugar, que Dios no sopora el mal y el sufrimiento que caen sobre el inocente y el justo, sino que desea que aque- 
llos desaparezcan. Nos ha llevado a comprender también que el ser humano está llamado a eliminar el mal y el sufrimiento de la humanidad, en la medida de sus limitadas posibilidades. Nos ha llevado a comprender, finalmente, que Dios esta al lado del inocente sufriente. que ha escuchado el llamado y se ha puesto a luchar hasta la saciedad y la muerte para que el mal y el sufrimiento sean eliminados de nuestro mundo.

Queda pendiente la pregunta del por que de todo eso; en otras palabras, si la última palabra de la historia no será el mal y el sufrimiento, sino el bien y la vida llena de dignidad. A eso quiere responder el libro de Job, que analizaremos en un proximo articulo, aunque ya hay indicios de respuesta, en lo que bemos escrito.

Aquf, desde El Salvador, terminamos con una reflexión muy actual sobre lo que hemos visto en los profetas. Monseñor Romero e Ignacio Ellacuria, dentro de una gran tradición meririal, dejaron una clara convicción de que existe el sufrimiento masivo e injusto, sobre todo de las mayorias pobres y victimas. Pero insistieron en que, cargando con el sufrimiento, se pueden buscar caminos de salvación y de liberación. Mús aún, que esas mayorías, y quienes se solidarizan con ellas, son hoy el siervo sufriente de Yaveh, el pueblo crucificado, que trae salvación. Quizís esté aquf el aporte más importante de la teologla surgida en El Salvador, en los últimos años, intuida y expuesta magistralmente por Ignacio Ellacuria, en su conocido texto "El pueblo crucificado, ensayo de soteriología histórica", Revista Latinoamericana de Teologia 18 (1989), pp. 305-333. 